\title{
Relationship between Obesity and Physical Fitness in School-Going Children of Anand District
}

\author{
Shah Dipika P
}

\begin{abstract}
Aim: To find the correlation between obesity and physical fitness in school-going children. Method: 1034 children of various schools of Anand were enrolled in the study. Obesity was evaluated using BMI, WC, WHtR and Sum of skinfold thickness (anterior thigh, suprailiac and anterior abdominal). 6 minute walk distance was measured by the standard ATS guidelines, as a parameter for physical fitness. Results: In 5- 11 years age-group children, for both boys and girls, there was significant positive moderate correlation between obesity and physical fitness. In boys and girls of $12-18$ years age-group, there was no significant relationship between obesity and physical fitness. Conclusion: Obesity and physical fitness are having positive relationship with each other in 5-11years age-group. However, due to the cross-sectional type, the implications of the study should be made carefully.
\end{abstract}

Shah Dipika P.

Assistant Professor

Ashok \& Rita Patel Institute of Physiotherapy

Charusat, Changa, Anand-388421, Gujarat, India

E-mail: drdipika83@gmail.com
Key Words: Childhood Obesity, Physical Fitness, BMI, 6MWD, WC, WHtR

DOI: $10.18376 / j e s p / 2017 / v 13 / i 2 / 111280$

\section{Introduction}

In the present world, it has been found that the prevalence and secondary co-morbidities of communicable diseases has been replaced by the outstanding rise of the non-communicable diseases (Ellulu, 2014).In the developing countries, the medical health force was working behind the management of malnutrition and infectious diseases found in the children and adolescent's agegroup (Kalra, 2012).WHO has listed obesity as the top most priority in the developed as well as the developing countries. Obesity has not only created a huge economic and health burden but has also contributed to the grave health concerns of the future generation (Ferreira et al, 2014). Obesity is defined as the presence of excessive fat tissue in the body (Tenorio, 2012). Childhood obesity is documented to be having the largest negative effects on the overall health of the child which is often not identified in the early stages (Brunet, 2007; Praveen, 2016). Many of the implications of obesity are also found to be persisting into adulthood (Boddy, 2010). Some of the diseases which are found to be secondary to obesity are type II diabetes, stroke, hypertension, depression, cancer, dyslipidemia and cardiovascular-respiratory diseases (Praveen, 2016; Byrd-Williams, 2008). Urbanization and modernization has resulted into enormous changes in overall health, transport, environment, food preferences with increasing screen-time. With the increased preference of children for junk food, leisure activities such as computer games, internet surfing, TV viewing and reduction in the outdoor sports due to safety and lack of play-grounds have promoted the imbalance between energy intake and energy output and thus thrusting the foundation of obesity in children (Ranjani et al, 2014; Beyerlein, 2011). Obesity can be assessed using various laboratory and field methods. In Asian population there is high predilection of central obesity in combination with low muscle mass and short stature, the commonly used measures may not assess obesity with great 
accuracy. In order to yield accurate results, multiple measures of obesity are taken. Also, while determining obesity, cooperation of children is necessary for measurements. Majority of the results have reported obesity being assessed by BMI, waist circumference, waist height ratio and skin-fold thickness measures (Malina, 2001; Deurenberg, 1990; Ganley et al, 2011; Ostojic, 2011).The development of cardio-respiratory diseases is laid upon the foundation of reduced physical fitness which is found to be associated with body composition measures (Dumith et al, 2010; Milanese, 2010). Physical fitness is the capacity to perform daily tasks without experiencing fatigue. It is broadly categorised into skill-related and health-related fitness (Malina, 2001; Ganley et al, 2011). Of the two, health-related fitness is the domain which is documented to be getting affected the most. Overweight/obesity and physical fitness seem to be 2 different parameters but it is found often that the changes in one can affect the other in varied strength (Aires, 2009). Over the last few years, it has been observed in many researches about the decline in the physical fitness and at the same end childhood obesity has been reaching newer epics globally. Obesity and physical fitness both are components of health which can track from childhood to adulthood and even in the elderly years(Dumith et al, 2010; Aires, 2009). Last few years have witnessed an increase in the prevalence of childhood obesity with many studies done in different regions of India. Due to the cultural variations found in India, ranges of factors which can affect the physical fitness of children are endless. To our knowledge there are no studies done in the Anand district wherein the relationship of obesity with physical fitness in children is explored. The benefits of the establishment of this relationship can be multifold, as physical fitness is more predictive for the health of it can guide in the framing of health policies in future and that the improvement in physical fitness in childhood can benefit an individual in the long run of life.

\section{Materials and Methods}

The population for the research is all the school going children of Anand District between the age of 5 years and 18 years. The sampling techniques used were Stratified Random Sampling to collect the sample from the population. The population was broadly divided into four strata viz. i) Boys from school of rural area, ii) Girls from school of rural area, iii) Boys from school of urban area, and iv) Girls from School of urban area. The sample size is calculated by using following formula.

$$
\begin{aligned}
& \mathrm{n}=\mathrm{Z}^{2} \mathrm{P}(1-\mathrm{P}) / \mathrm{d}^{2} \\
& \text { where, } \\
& \mathrm{n}=\text { Sample Size } \\
& \mathrm{Z}=\mathrm{Z} \text { statistics for level of confidence (1.96 in this study at } 95 \% \text { level of confidence) } \\
& \mathrm{P}=\text { Expected Prevalence } \\
& \mathrm{d}=\text { Level of precession }(5 \%(0.05) \text { in present study) }
\end{aligned}
$$

Based on prevalence, of every stratum on data collected during pivot phase, the sample size is 1034 out which 238 were boys from rural area, 183 were girls from rural area, 273 were urban boys and 340 were urban girls.

School children from both sexes in the age-group of 5-18 years, belonging to Government and Private schools, located in four different geographical zones in Anand district were studied. The study protocol was approved by the Institutional Review Board of our Institute. A prior consent for the study was taken from the school administration. In children above 7 years of age, a written consent was taken from the school teacher in addition to the written assent given by the child. In children below 7 years of age, a written consent form was signed by the respective school teacher (legal guardian). Obesity was evaluated using BMI (IOTF Classification), Waist Circumference (WC) and Waist-Height ratio (WHtR). The entire cohort of 1034 children and adolescents underwent assessment of height and weight and calculation of BMI. Height was measured using a stadiometer with the subject standing straight with head held in the horizontal plane. Subject's weight, without shoes on with light clothes on was measured to using a digital scale. Height and 
weight measurements were taken twice and the mean of two measurements was used to calculate BMI, which was defined as the ratio of body weight to body height squared, expressed in $\mathrm{kg} / \mathrm{m} 2$. Every morning, the weighing scale and stadiometer were calibrated with standard weight and height respectively. The cut-off values of IOTF BMI classification, at each age and for each gender, were used to classify children as Overweight and Obese. Waist circumference and height for each subject was measured with the child standing, without heavy outer garment and with empty pockets, using a tape. The waist circumference was measured at the level midway between the lower rib margin and the iliac crest, at the umbilicus, with the child breathing out gently. From the waist circumference and height, the waist to height ratio was calculated. For physical fitness, 6 minute walk distance was calculated. It is a simple, safe and well established assessment tool used to quantify the physical fitness in individuals. American Thoracic Society guidelines were followed for the conduction of the test. The location of the test was usually allotted by the school authorities in a place which was within the school campus where there was no least number of disturbances. The walkway was marked as $30 \mathrm{~m}$ in length, with a mark at every $3 \mathrm{~m}$. The turns in the walkway were marked with a cone. The child was wearing the school uniform with school shoes during the performance of the test. Appropriate chair was kept at the starting point of the walkway, on which the child was made to sit for 10 minutes prior to the start of the test. Before the start of the test, following instructions were given to the child, "You are supposed to walk for 6 minutes on this marked distance at a comfortable pace. You are supposed to walk back and forth around the cones. If you feel uncomfortable or get tired then you can stop walking. I will be providing the chair immediately for you to sit. I will be keeping the track of the number of laps you complete. You can walk as fast as you can but running and jogging is not allowed." Then the researcher was giving a demonstration of walking one lap, after which the child performed the test. Words of encouragement, "Keep up the good work" were told to the child as the time passed. The test was terminated as soon as the child complained of any discomfort or fatigue. The number of completed laps as well as the additional distance (number of meters in the final partial lap) covered. The total distance walked, rounding to the nearest meter was noted down (ATS Statement, 2002)

\section{Results}

In the present study, obesity was evaluated using waist-height ratio. Normality testing of the data revealed that it was not normally distributed. Hence, spearman correlation coefficient was calculated for various variables such as socio-economic status, gender and age-group classification.

Table1. Correlation between physical fitness \& Obesity

\begin{tabular}{|l|l|l|l|l|l|l|l|l|l|}
\hline \multirow{2}{*}{$\begin{array}{l}\text { Age } \\
\text { (years) }\end{array}$} & \multirow{2}{*}{ Gender } & \multicolumn{2}{|c|}{ BMI } & \multicolumn{2}{c|}{ WC } & \multicolumn{2}{c|}{ WHtR } & \multicolumn{2}{c|}{ SSFT } \\
\cline { 3 - 10 } & & Obese & $\begin{array}{l}\text { Non- } \\
\text { obese }\end{array}$ & Obese & $\begin{array}{l}\text { Non- } \\
\text { obese }\end{array}$ & Obese & $\begin{array}{l}\text { Non- } \\
\text { obese }\end{array}$ & Obese & $\begin{array}{l}\text { Non- } \\
\text { obese }\end{array}$ \\
\hline \multirow{2}{*}{$\mathbf{5 - 1 1}$} & Boys & $0.53^{*}$ & $0.30^{*}$ & $0.72^{*}$ & $0.59^{*}$ & 0.04 & $-0.19^{*}$ & $0.55^{*}$ & $0.58^{*}$ \\
\cline { 2 - 10 } & Girls & $0.63^{*}$ & 0.11 & $0.65^{*}$ & $0.56^{*}$ & 0.17 & -0.12 & $0.48^{*}$ & $0.50^{*}$ \\
\hline \multirow{2}{*}{$\mathbf{1 2 - 1 8}$} & Boys & -0.20 & 0.09 & 0.01 & $0.19^{*}$ & -0.15 & 0.07 & $0.22^{*}$ & 0.02 \\
\cline { 2 - 10 } & Girls & -0.11 & 0.04 & 0.21 & 0.06 & 0.12 & -0.03 & -0.25 & -0.01 \\
\hline
\end{tabular}

5-11 years age-group (Obese): Boys had significant positive moderate correlation between 6MWD and $\operatorname{BMI}(0.53, \mathrm{p}<.01)$, WC $(0.72, \mathrm{p}<0.01) \& \operatorname{SSFT}(0.55, \mathrm{p}<0.01)$. Girls also had significant positive moderate correlation between $6 \mathrm{MWD}$ and $\mathrm{BMI}(0.63, \mathrm{p}<0.01)$, WC $(0.65, \mathrm{p}<0.01) \&$ SSFT $(0.48, \mathrm{p}<0.01)$. 5-11 years age-group (Non-obese): Boys had significant positive low correlation between 6MWD and $\operatorname{BMI}(0.30, \mathrm{p}<0.01)$, significant positive moderate correlation between WC $(0.59, \mathrm{p}<0.01) \&$ SSFT $(0.58, \mathrm{p}<0.01)$. Girls had significant positive moderate correlation between $6 \mathrm{MWD}$ and WC $(0.56, \mathrm{p}<0.01) \& \operatorname{SSFT}(0.50, \mathrm{p}<0.01) .12-18$ years age-group (Obese): Boys had 
significant positive low correlation between only between 6MWD and SSFT $(0.22, \mathrm{p}<0.01)$. Girls did not have significant correlation between any of the obesity parameters and 6MWD. $12-18$ years age-group (Non-obese): Boys had significant positive low correlation between 6MWD and WC $(0.19, \mathrm{p}<0.01)$. Girl did not have significant correlation between any of the obesity parameters and 6MWD.

\section{Discussion}

For boys of 5-11 years of age-group, there was variation in the positive correlation in terms of BMI between obese and non-obese group indicating that there was no difference in the fitness levels of boys with and without obesity. With the increase in BMI of boys their fitness level was also raising, depicting that obesity was not having its deleterious effect on the physical fitness of boys. This implies that during the performance of any task which requires increased energy to generate ventilation increases the perception of discomfort with breathing and at the same time the proportional assisted ventilation, decreases the inspiratory work of breathing in turn increasing exercise performance and reduces dyspnea in obese subjects (Babb, 2013). Additionally, BMI reflects adipose tissue and also muscle and bones. Association between BMI \&physical fitness also has a component of respiratory muscle strength. In children, increased BMI is associated with decreased lung function. In childhood obesity, increased BMI is accompanied with absence in the changes of spirometric values because increased muscle strength is linked with increasing lean muscle mass (Fariaet al, 2014). It may be also because BMI is sex, age, level of maturity and leg length dependent measure which cannot differentiate between fat and fat-free mass (Rerksuppaphol, 2013). BMI underestimates the cardio-metabolic risk in normal weight \& overestimates it in obese children (Mokha et al, 2010) and hence may not have been able to detect the change in physical fitness of children due to obesity. The same applies to the difference in the positive correlation in terms of WC and SSFT in boys with and without obesity. This clearly indicates that the pattern of fat distribution between obesity and non-obese boys is similar. WC increased with the increase in age. WC has been rated as a good predictor of cardiovascular factors, insulin resistance, blood pressure, serum cholesterol, triglycerides and metabolic syndrome (Bacopoulou, 2015). In terms of WHtR, there was negative correlation of low strength in non-obese children. In obese children there was no significant correlation between obesity and 6MWD. This signifies that obesity did not have negative effect on the physical fitness in boys. In non-obese boys, the poor strength of negative correlation may be due to the fact that children who were screened by WHtR in the non-obese category were having appropriate weight with reference to their matched height. For girls of $5-11$ years, there was positive correlation of moderate strength between obesity and 6MWD in obese group, whereas in non-obese group there was no significant correlation between BMI \& 6MWD. This may be because as per IOTF classification of BMI, the non-obese group consists of individuals who may be underweight as well as normal weight children. Thus, this mixed category of children might have yielded insignificant results in non-obese group. With reference to, WC \& 6MWD and SSFT \& 6MWD, there was a small difference in the correlation values between obese and nonobese girls signalling to the fact that the pattern of fat distribution was same between both the groups. Due to the favourable fat distribution in the peripheral depots and not over the abdominal region, obesity could not affect their fitness levels. Majority of fat is stored in subcutaneous layers, another major part of fat is stored in intra-abdominal depots and muscles \& liver which are sensitive to insulin levels. So whenever there is an increase in fat the circulation of free fatty acids is increased to a great extent in the portal circulation. The ratio of visceral fat: subcutaneous fat is stronger predictor than the total fat deposition indicating that the obese individuals with high ratio are at an increased risk than the more obese individuals with lower ratios (Weiss, 2013).Distribution of fat is also affected by sex hormones, in males the intra-abdominal fat portion is more than that in females (Ochiaiet al, 2015). Early sexual maturation in girls is also associated with the increased 
obesity prevalence of obesity (Ostojic, 2011). Obese children have to carry heavy limbs during exercise, so exercise intolerance is more in obese than normal children, but it is not due to a true decrease in cardio-respiratory fitness. Past researches demonstrate that during unloaded cycling it was observed that by just moving their fat limbs, was resulting into increase in absolute oxygen uptake, consumption of large proportion of cardio-respiratory reserve (Norman, 2005). Due to obesity, children have to move larger limbs, increased weight of body and change in breathing mechanics, which is observed during exercise. Respiratory neural drive is usually the one which controls ventilation. But in obesity, ventilation is within normal limits relative to increased oxygen demand but respiratory neural drive is changed to give normal ventilation (Babb, 2013). So, in our study, the physical fitness status of obese children was found at nearly same level as that of nonobese individuals. In obese children, during exercise, there is higher oxygen pulse rate because it depends on stroke volume and arteriovenous difference. During maximum exercise, in obese individuals the arteriovenous difference is same as that in normal weight individuals. So, the higher oxygen which is followed by increase in stroke volume is just like people who have higher levels of fitness. Therefore, obese people have higher physical fitness, because they are already trained to carry excess weight which mimics resistance training (Sereset al, 2003). In boys and girls of $12-18$ years of age, there was no significant correlation between BMI \& 6MWD and WHtR \& 6MWD in both obese and non-obese children. In terms of WC \& 6MWD, there was positive correlation of low strength in the non-obese group of boys. BMI reflects total obesity, but health risks are correlated with central obesity, so many authors advocate the use of WC \& WHtR as compared to BMI (Rodea-Montero, 2014; Zhang, 2016). WC can identify $>90 \%$ of children as being truly positive (high waist circumference and high trunk fat mass) or truly negative (low waist circumference and low trunk fat mass) as measured by DXA (Taylor, 2000). Waist-height ratio is a better indicator than WC, because WC may change in same age and sex matched individuals with varying height. Height of children with same age and sex can range within $28 \mathrm{~cm}$. Studies have proven that individuals with same WC but shorter heights can have greater metabolic risks. Also, there are growth spurts during childhood and adolescence which indicates that WC would also seize to be a better predictor for metabolic syndrome. Growth in obese adolescents does not decrease WC if their lifestyles are not modified (Rodea-Montero, 2014). But when the correlation of height with all the parameters of obesity and physical fitness was analysed it was found that there was no effect of the child's height irrespective of their obesity status. Thus, height was influencing both the obese and non-obese groups in a similar manner. With reference to SSFT \& 6MWD, there was positive correlation of very low strength established in boys. The above observation again points out to the fact that deposition of fat was more in the peripheral depots than the visceral fat depots. From the past researches, some argue that the response to exercise or any physical strenuous activity in obese children, is in normal limits but their exercise capacity is compromised as they have large body mass. Some others argue that they have reduced aerobic capacity because their fat mass interferes with cardiac \& pulmonary function and thus limiting aerobic response to exercise. The results are like this because these researches have employed various outcome measures of obesity and physical fitness and have studied various ethnicity individuals with different age (Norman, 2005). In most of the studies involving field analysis, for evaluation of physical fitness, 6MWT is preferred over other laboratory tests. In our study we had used 6MWD to study their physical fitness because it has following benefits such as walking is one of the normal activities of life reflecting the capacity to do daily activities (Makniet al, 2012), it is simple, easy to administer, it has low cost and can be used in routine (Makni et al, 2012; Kanburoglu, 2014; Roush, 2006; Geiger et al, 2010; Ulrich et al, 2013) validated to have high correlation with workloads, HR, oxygen saturation \& dyspnoea responses when compared with standard cycle ergometry\& treadmill exercise tests (Makniet al, 2012; Kanburoglu, 2014; Roush, 2006; Ulrich et al, 2013), direct correlation with quality of life 
which enables an individual to cope against disease process and remain independent (Makniet al, 2012; Ulrich et al, 2013), provides opportunity to evaluate patient in a timely, practical and economical manner (Makniet al, 2012; Ulrich et al, 2013), repeated measurements are possible as the patient has to be evaluated in a disease progression manner(Makniet al, 2012; Geiger et al, 2010; Ulrich et al, 2013) relationships found between 6MWD and crude power and / or HR at which fat oxidation reaches its maximum is the most useful information in targeting the planning of training procedure (Makni et al, 2012; Geiger et al, 2010. However, there are various drawbacks of $6 \mathrm{MWD}$ as it may not change with increase in age because of ever-changing hormones and energy levels or discrepancy of inner motivation of children at different ages. During a self-paced test, motivation is very important and no qualifying criteria for a 6MWT in children have been identified. 6MWD does not differ between active and very active but it can differentiate between sedentary and very active individuals (Kanburoglu, 2014). 6MWD is influenced by height, weight, ethnical background, age and developmental stage. There is lack of validity to describe 6MWD in percentage as in adults, it can be interpreted that the influence of age and other growth parameters has a huge influence on 6MWD values in children, as compared to adults (Ulrich et al, 2013). It may also be possible that the normal weight children in our study might have central obesity with high levels of cardio-metabolic risks compared to those without central obesity. Obese children with central obesity have higher risks of cardiometabolic parameters than those without central obesity - this is indicative of the variant of obesity which is labelled as metabolically healthy obese \& metabolically obese normal weight (Mokha et al, 2010). Metabolic syndrome is a temporary phenomenon because researches show that obese children who grew up as non-obese adults had the same level of risks as those individuals who were never obese. $30 \%$ of obese individuals can be metabolically healthy (Tendera-Malecka, 2014). Metabolic syndrome is not defined well in paediatric population because of the following reasons: 1. Lack of centralized obesity measures, 2 . Lack of normal ranges of insulin assays, 3. Metabolic parameters appearing abnormal in adults are actually moderate in children, 4 . Laboratory parameters are defined by the threshold value but many a times these values reflect the gradual development of this risk in process which gets hidden in the threshold value range, 5. Ethnic background in the children also denote the variations in which lipid gets deposited in the various parts of our body which acts as a strong indicator of the insulin resistance and cardiovascular risks (Weiss, 2013). Adult definition of Metabolic syndrome consists of elevated TG level, reduced HDL - C level, raised BP, elevated fasting glucose, increased WC. Almost all definitions have included the presence of some combinations of these factors rather than the presence of all factors rather than the presence of all factors. So only, obesity in childhood has been considered as a strong predictor of metabolic syndrome. But as compared to obesity, lipid partitioning is considered as a major factor for metabolic syndrome rather than the level of obesity (Weiss, 2013). At this point it is not possible to identify the children in our study of having metabolic syndrome, because WC is the only parameter which was studied in the present study. Also, metabolic syndrome is difficult to define in children because the normal reference range of HDL, TG, WC \& BP are lacking, MS cannot be diagnosed in children <6 years of age, visceral fat distribution which is critical for MS in children and cardiovascular diseases in adults, can be measured best by WC, but reference values of WC exists only for few countries, but no organization considers WC as the standard measure. Prevalence of metabolic syndrome in children has been documented between $21 \%$ and $68 \%$ (Das, 2014). Other contributing factors are the family history of diabetes, cardiovascular disease, low birth weight, early versus late growth and maturation patterns, socio-economic status in childhood, sedentary behaviour \& specific dietary constituents (Weiss, 2011) which can also affect the physical fitness of children at a varying impact level. 
The design of the study is cross-sectional in nature which limits the implication of causalrelationship between obesity and physical fitness. The study of other factors related to obesity such as the dietary pattern, levels of physical activity, genetics and built-in environment. With regards to $6 \mathrm{MWD}$, the lack of normal healthy values of children hinders the clinical application of this test in the pediatric age-group.

\section{Conclusion}

Obesity and physical fitness are having positive moderate relationship with each other in boys and girls of 5-11 years age-group. But the same kind of relationship was not observed in children of 1218 years age-group. However, the confounding factors which might have obscured the results of the study need to be considered before taking the results of the study for future clinical practice.

\section{Acknowledgements}

Our foremost thanks to the participants without whose support the research would not have been possible.

\section{References}

Aires LMSMC, Mota DJAP, 2009. Levels of physical activity, physical fitnesss and overweight/ obesity in children and adolescents. Doctoral Dissertation, Faculty of Sports - University of Porto

ATS Statement: Guidelines for the Six-Minute Walk Test. American Journal of Respiratory and Critical Care Medicine, 2002; 166(1): 111-117.

Babb TG. Obesity: Challenges to ventilatory control during exercise a brief review. Respiratory Physiology \&Neurobiology, 2013; 189(2): 364-370.

Bacopoulou F, Efthymiou V, Landis G, Rentoumis A, Chrousos GP. Waist circumference, waist-to-hp ratio and waist-to-height ratio reference percentiles for abdominal obesity among Greek adolescents. BMC Pediatrics, 2015;15:50.

Beyerlein A, Toschke AM, Rosario AS, Kries R. Risk factors for obesity: Further evidence for stronger effects on overweight children and adolescents compared to normal-weight subjects. PLoS ONE, 2011; 6(1): e15739.

Boddy LM, Hackett AF, Stratton G. Changes in fitness, body mass index and obesity in 9-10 year olds. Journal of Human Nutrition and Dietetics, 2010; 23(3): 254-259.

Brunet M, Chaput JP, Tremblay A. The association between low physical fitness and high body mass index or waist circumference is increasing with age in children: the 'Quebec en Forme' Project. International Journal of Obesity, 2007; 31(4): 637-643.

Byrd-Williams CE, Shaibi GQ, Sun P, Lane CJ, Ventura EE, Davis JN, Kelly LA, Goran MI. Cardiorespiratory fitness predicts changes in adiposity in overweight Hispanic boys. Obesity, 2008; 16(5): 1072-1077.

Das VL, Purohit P, Sharma P, Das A. Metabolic syndrome in pediatric age - a group requiring intensive review. Journal of Obesity and Metabolic Research, 2014; 1(4): 238-244.

Deurenberg P, Pieters JJL, Hautvast JGAJ. The assessment of the body fat percentage by skinfold thickness measurements in childhood and young adolescence. British Journal of Nutrition, 1990; 63 (2): 293-303.

Dumith SC, Ramires VV, Souza MA, Moraes DS, Petry FG, Oliveira ES, Ramires SV, Hallal PC.Overweight/Obesity and physical fitness among children and adolescents. Journal of Physical Activity and Health, 2010; 7(5): 641-648.

Ellulu M, Abed Y, Rahmat A, Ranneh Y, Ali F. Epidemiology of obesity in developing countries: challenges and prevention. Global Epidemic Obesity, 2014; 2(2).

Faria AG, RibeiroMAGO,Marson FAL, Schivinski CIS, SeverinoSD, Ribeiro JD, Filho AAB. Effect of exercise test on pulmonary function of obese adolescents.Jornal de Pediatria, 2014; 90(3): 242-249.

Ferreira MS, Mendes RT, Marson FA, Zambon MP, Paschoal IA, Toro AADDC, Severino SD, Ribeiro MAGO, Ribeiro JD. The relationship between physical functional capacity and lung function in obese children and adolescents. BMC Pulmonary Medicine, 2014; 14: 199.

Ganley KJ, Paterno MV, Miles C, Stout J, Brawner L, Girolami G, Warren M. Health-related fitness in children and adolescents. Pediatric Physical Therapy, 2011; 23(3): 208-220. 


\section{Journal of Exercise Science \& Physiotherapy, Vol. 13, No. 2, 2017 \\ ISSN: $0973-2020$ (Print) $\quad \mathrm{I}_{2}$ OR Impact Factor = 5.23 UGC Approved [Journal No.7485] ISSN: 2454-6089 (online)}

Geiger R, Willeit J, Rummel M, Hogler W, Stubing K, Strasak A, Geiger H, Stein JI, Rauchenzauner M. Sixminute walk distance in overweight children and adolescents: Effects of a weight-reducing program. The Journal of Pediatrics, 2010; 158(3): 447-451.

Kalra S, Unnikrishnan AG. Obesity in India: The weight of the nation. Journal of Medical Nutrition and Nutraceuticals, 2012; 1(1): 37-41.

Kanburoglu MK, Ozdemir FM, Ozkan S, Tunaoglu FS. Reference values of the 6 - minute walk test in healthy Turkish children and adolescents between 11 and 18 years of age. Respiatory Care, 2014; 59(9): 13691375.

Makni E, Moalla W, Trabelsi Y, Lac G, Brun JF, Tabka Z, Elloumi M. Six-minute walking test predicts maximal fat oxidation in obese children. International Journal of Obesity, 2012; 36(7): 908-913.

Malina RM. Physical activity and fitness: Pathways from childhood to adulthood. American Journal of Human Biology, 2001; 13(2): 162-172.

Milanese C, Bortolami O, Bertucco M, Verlato G, Zancanaro C. Anthropometry and motor fitness in children aged 6-12 years. Journal of Human Sport \& Exercise, 2010; 5(2): 265-279.

Mokha JS, Srinivasan SR, Dasmahapatra P, Fernandez C, Chen W, Xu J, Berenson GS. Utility of waist-toheight ratio in assessing the status of central obesity and related cardiometabolic risk profile among normal weight and overweight/obese children: the Bogalusa Heart Study. BMC Pediatrics, 2010; 10:73.

Norman AC, Drinkard B, McDuffie JR, Ghorbani S, Yanoff LB, Yanovski JA. Influence of excess adiposity on exercise fitness and performance in overweight children and adolescents. Pediatrics, 2005; 115(6): e690-e696.

Ochiai H, Shirasawa T, Nishimura R, NanriH, Ohtsu T, Hoshino H, Tajima N, Kokaze A. Waist-to-height ratio is more closely associated with alanine aminotransferase levels than body mass index and waist circumference among population-based children: a cross-sectional study in Japan. BMC Pediatrics, 2015;15:59.

Ostojic SM, Stojanovic MD, Stojanovic V, Maric J, Njaradi N. Correlation between fitness and fatness in 6-14 year old Serbian school children. Journal of Health, Population and Nutrition, 2011; 29 (1): 53-60.

Praveen PA, Tandon N. Childhood obesity and type 2 diabetes in India. WHO South-East Asia Journal of Public Health, 2016; 5(1): 17-21.

Ranjani H, Pradeepa R, Mehreen TS, Anjana RM, Anand K, Garg R, Mohan V. Determinants, consequences and prevention of childhood overweight and obesity: An Indian context. Indian Journal of Endocrinology and Metabolism, 2014; 18(1):s17-s25.

Rerksuppaphol S, Rerksuppaphol L. Optimal cut-off points of weight for height, waist circumference and waist-to-height ratio for defining overweight and obesity in Thai school-aged children. Journal of Research in Health Sciences, 2013; 13(1): 13-18.

Rodea-Montero ER, Evia-Viscarra ML, Apolinar-Jimenez E. Waist-to-height ratio is a better anthropometric index than waist circumference and BMI in predicting metabolic syndrome among obese Mexican adolescents. International Journal of Endocrinology, 2014; 195407.

Roush J, Guy J, Purvis M. Reference values and relationship of the six minute walk test and body mass index in healthy third grade school children. The Internet Journal of Allied Health Sciences and Practice, 2006; 4(3).

Seres L, Lopez-Ayerbe J, Coll R, Rodriguez O, Manresa JM, Marrugat J, Alastrue A, Formiguera X, Valle V. Cardiopulmonary function and exercise capacity in patients with morbid obesity. Revista Espanola De Cardiologia, 2003; 56(6): 594-600.

Taylor RW, Jones IE, Williams SM, Goulding A. Evaluation of waist circumference, waist-to-hip ratio, and the conicity index as screening tools for high trunk fat mass, as measured by dual -energy X-ray absorptiometry, in children aged 3-19 years. American Journal of Clinical Nutrition, 2000; 72: 490-495.

Tendera-Malecka E. Healthy obese child; when and in whom do comorbidities develop? Nutrition, Obesity \& Metabolic Surgery, 2014; 1(1): 10-13.

Tenorio LHS, Santos AC, Oliveira AS, Lima AMJ, Brasileiro-Santos MS. Obesity and pulmonary function tests in children and adolescents: a systematic review. RevistaPaulista de Paediatria, 2012; 30(3): 42

Ulrich S, Hildenbrand FF, Treder U, Fischler M, Keusch S, Speich R, Fasnacht M. Reference values for the 6minute walk test in healthy children and adolescents in Switzerland. BMC Pulmonary Medicine, 2013; 13: 49 . 
Weiss R. Childhood metabolic syndrome - Must we define it to deal with it? Diabetes Care, 2011; 34(2): s171 $-\mathrm{s} 176$.

Weiss R, Bremer AA, Lustig RH. What is metabolic syndrome, and why are children getting it? Annals of the New York Academy of Sciences, 2013; 1281(1): 123-140.

Zhang Y, Zhao J, Chu Z. More attention should be paid to monitoring of abdominal obesity among children and adolescents. Annals of Nutrition \& Metabolism, 2016; 69(3-4): 212-214.

Conflict of Interest: None Declared 